\title{
Dydrogesterone usage pattern in India: a knowledge, attitude and practice survey among Indian gynaecologists
}

\author{
Geeta Khanna ${ }^{1}$, Madhuri Dabade ${ }^{2}$, Sajal Dutta, ${ }^{3}$ Nitin Deshpande ${ }^{4}$, Girish Mane ${ }^{5}$, \\ Chetna Shah ${ }^{6 *}$, Girish Deshmukh ${ }^{6}$
}

\author{
${ }^{1}$ Ajanta Hospital and IVF Centre, Lucknow, Uttar Pradesh, India \\ ${ }^{2}$ Krishna Mai Nursing Home and Test tube baby Centre, Solapur, Maharashtra, India \\ ${ }^{3}$ Ramakrishna Mission Seva Pratishthan, Kolkata, West Bengal, India \\ ${ }^{4}$ Sushila Nursing Home, Vasai, Maharashtra, India \\ ${ }^{5}$ Mane Hospital, Yavatmal, Maharashtra, India \\ ${ }^{6}$ Emcure Pharmaceuticals Ltd., Pune, Maharashtra, India
}

Received: 23 August 2021

Revised: 19 September 2021

Accepted: 20 September 2021

*Correspondence:

Ms. Chetna Shah,

E-mail: Chetna.Shah@emcure.co.in

Copyright: (C) the author(s), publisher and licensee Medip Academy. This is an open-access article distributed under the terms of the Creative Commons Attribution Non-Commercial License, which permits unrestricted non-commercial use, distribution, and reproduction in any medium, provided the original work is properly cited.

\section{ABSTRACT}

Background: There is limited data about the knowledge, perception, and routine clinical usage pattern of dydrogesterone among medical practitioners in India. Therefore, the present survey was undertaken to assess attitudes and perception/practices of obstetrician and gynaecologists towards use of dydrogesterone in the real-life setting.

Methods: Total 1168 gynaecologists across India participated in the KAP survey. Sixteen questions which explored indications, dosages, duration, efficacy, tolerability and comparison were asked and results were expressed as percentages.

Results: Dydrogesterone has been marketed since the 1960s and has been extensively used worldwide for the treatment of threatened miscarriage (TM) and recurrent miscarriage (RM). Dydrogesterone is approved for hormone replacement therapy (HRT), as well as pregnancy and non-pregnancy-related conditions where there is a progesterone deficiency. In the present survey, dydrogesterone $10 \mathrm{mg}$ twice daily was found to be the most commonly preferred dosage by 823 (73\%) gynaecologists. Poor tolerability, compliance and lower efficacy were reported as major limitations of micronized progesterone by $68 \%$ of doctors. The average clinical pregnancy rate noted at 12 weeks after Dydrogesterone usage was around $40 \%$ by majority of the doctors. However, $30 \%$ of doctors noted more than $40 \%$ of clinical pregnancy rate after dydrogesterone usage. Almost $35 \%$ of doctors reported that the average live birth rate noticed after dydrogesterone usage is around $40 \%$.

Conclusions: The present KAP survey highlights that the effectiveness and the tolerability of dydrogesterone is valued by Indian gynaecologists which accounts for its robust clinical utility.

Keywords: KAP survey, Threatened miscarriage, Recurrent miscarriage, Luteal phase support, India

\section{INTRODUCTION}

Progesterone is required for creating a suitable endometrial environment for embryo implantation and for the maintenance of pregnancy. Progesterone is also believed to help in mediating an anti-inflammatory immune response to the allogenic foetus and in inducing uterine smooth muscle relaxation. ${ }^{1-3}$ Progestogens have been used extensively in an attempt to overcome progesterone deficiency associated with infertility and 
miscarriage. ${ }^{3}$ Different progestogens varies in their progestogenic potency, receptor-binding selectivity, bioavailability, and route of administration and these factors determine selection of the most appropriate agent for each condition. ${ }^{3}$ Micronized progesterone is in use since $1980 \mathrm{~s} .{ }^{4}$ Because of low and variable bioavailability, micronized progesterone is administered orally with high doses, which results in side effects such as drowsiness, nausea, and headaches. ${ }^{5}$ With these reasons, micronized progesterone is typically administered vaginally. However intravaginal micronized progesterone may not be fully absorbed, may be washed out with vaginal bleeding, and may cause local irritation. ${ }^{6}$

So, alternative progestogens have become widely used for obstetric indications. One of those is dydrogesterone or 6dehydro-retroprogesterone, which has a molecular structure closely related to that of natural progesterone. ${ }^{3}$ It is administered orally and has reported 5.6 times higher bioavailability than that of progesterone. ${ }^{7}$ Dydrogesterone is highly selective for the progesterone receptor. ${ }^{3}$ It is estimated that dydrogesterone requires a 10-20 times lower oral dose compared with micronized progesterone. ${ }^{3}$ Currently there is limited data about the knowledge, perception, and routine clinical usage pattern of dydrogesterone among medical practitioners in India. The present survey was undertaken to explore the knowledge, perception, and usage of dydrogesterone by Indian gynaecologists in the real-life setting. The aim of this survey was to study the usage of progesterone in current clinical practice, and to study the advantages of dydrogesterone over natural micronized progesterone.

\section{METHODS}

\section{Survey design and setting}

This was a prospective, cross-sectional, observational, questionnaire-based survey conducted across India from December 2020 to Feb 2021. The flow of the study was: administration of the questionnaire to Obstetrician and Gynaecologist who gave consent, followed by filling of questionnaire based on prior clinical experience and knowledge of usage of dydrogesterone, collection of questionnaires, compilation, analysis and presentation of data.

\section{Survey participants}

The KAP survey was facilitated by the authors. Registered medical practitioners with recognized qualifications in Gynaecology and working in outpatient departments of public and privately run clinics/hospitals participated in this survey. The survey consisted of total 1168 gynaecologists across all over India.

\section{Survey instrument}

The survey questionnaire was specially designed, selfcompletion and structured, which included 16 multiple choice questions. The survey assessed the gynaecologists' knowledge, attitude, and practice toward the use of dydrogesterone in routine clinical practice. It was a voluntary survey and therefore it was not necessary to answer all the questions and participants were free to choose more than one response to a question if desired and suitable.

Knowledge here refers to knowledge about dydrogesterone. The knowledge based questions were as followed: Average number of patient with recurrent pregnancy loss in a month, patients most suitable for treatment with dydrogesterone, $\%$ of patients requiring treatment with dydrogesterone, preferred dose of dydrogesterone and most important and critical factors for selecting dydrogesterone in routine clinical practice.

Attitude refers to the outlook of obstetrician and gynaecologist towards the efficacy and tolerability of dydrogesterone. The attitude based questions were as followed: limitations towards use of micronized progesterone in clinical practice, advantages of dydrogesterone over natural micronized progesterone, average clinical pregnancy rate noticed at 12 weeks after dydrogesterone usage and average live birth rate noticed after dydrogesterone usage.

The remaining seven questions related to practice were:

Preferred type of progesterone in clinical practice, average duration of dydrogesterone therapy used in case of recurrent miscarriage, duration for use of dydrogesterone in threatened abortion, preferred area for use of natural micronized progesterone, preference and conditions for co-administration of dydrogesterone and natural micronized progesterone and preference on indigenously developed products. This was a survey through which no patient related data was captured and therefore ethics committee approval was not necessary and hence not obtained. As this was not a clinical trial, no clinical trial registration was required.

\section{Data analysis}

Descriptive statistics were used to summarize the qualitative data by number (n) and percentage for each category in each question. This data was graphically represented as bar diagrams. Not all participants answered all the questions and many participants responded to more than one option for many of the questions if desired and suitable. The denominator for calculating proportion for a particular question was total number of participants replied to a particular question and the ' $n$ ' has been appropriately marked in each graph.

\section{RESULTS}

Total 1168 Obstetrician and gynaecologists participated in this survey across India, out of whom, all 1168 completed the survey. 
Table 1: Average dose of dydrogesterone.

\begin{tabular}{|lll|}
\hline $\begin{array}{l}\text { Average dose of } \\
\text { dydrogesterone }\end{array}$ & $\begin{array}{l}\text { No. of } \\
\text { doctors }\end{array}$ & $\%$ \\
\hline $\mathbf{1 0}$ mg once daily & 171 & 15 \\
\hline $\mathbf{1 0} \mathbf{~ m g}$ two times daily & 823 & 73 \\
\hline $\mathbf{1 0} \mathbf{~ m g}$ three times daily & 117 & 10 \\
\hline $\mathbf{2 0} \mathbf{~ m g}$ twice daily & 33 & 3 \\
\hline Other & 6 & 1 \\
\hline
\end{tabular}

Table 2: Preference on indigenously developed product.

\begin{tabular}{|lll|}
\hline $\begin{array}{l}\text { Preference on indigenously } \\
\text { developed product }\end{array}$ & $\begin{array}{l}\text { No. of } \\
\text { doctors }\end{array}$ & $\%$ \\
\hline Most preferred & 421 & 38 \\
\hline Preferred & 476 & 43 \\
\hline Neutral & 110 & 10 \\
\hline Does not matter & 108 & 10 \\
\hline $\begin{array}{l}\text { Total preference on indigenously } \\
\text { developed product (most preferred } \\
\text { + preferred) }\end{array}$ & 897 & 81 \\
\hline
\end{tabular}

Table 3: Factors for selection of Dydrogesterone.

\begin{tabular}{|lcc|}
\hline $\begin{array}{l}\text { Factors for selection of } \\
\text { dydrogesterone }\end{array}$ & $\begin{array}{l}\text { No. of } \\
\text { doctors }\end{array}$ & $\%$ \\
\hline Quality of product & 514 & 46 \\
\hline Clinical data & 229 & 20 \\
\hline Patient related outcomes & 478 & 43 \\
\hline Cost & 211 & 19 \\
\hline Other & 31 & 3 \\
\hline
\end{tabular}

Data from $688(59 \%)$ centres reports that, approximately 20 women with recurrent pregnancy loss usually visited every month. Dydrogesterone $10 \mathrm{mg}$ twice daily was the most commonly preferred dosage by $823(73 \%)$ of gynaecologists, while $171(15 \%)$ and $117(10 \%)$ of gynaecologists preferred to use $10 \mathrm{mg}$ OD and $10 \mathrm{mg}$ TID dosage of dydrogesterone respectively (Table 1).

Interestingly, $87 \%$ gynaecologists reported to use dydrogesterone in women with recurrent pregnancy loss, habitual abortion, threatened abortion and for luteal phase support (Figure 1). Near about 474 (42\%) of the gynaecologists reported to use dydrogesterone for up to 14 weeks in women with threatened abortion while 371 (33\%) of gynaecologists preferred to use dydrogesterone till 18 weeks in women with threatened abortion (Figure 2). Near about $412(36 \%)$ of the gynaecologists reported to use dydrogesterone in recurrent miscarriage for up to 10 to 14 weeks (Figure 3).

Total 337 (30\%) gynaecologists reported more than $40 \%$ of clinical pregnancy rate after 12 weeks of dydrogesterone usage (Figure 4). While, total 388 (35\%) gynaecologists reported the average live birth rate observed after 12 weeks dydrogesterone usage was $40 \%$ (Figure 5).

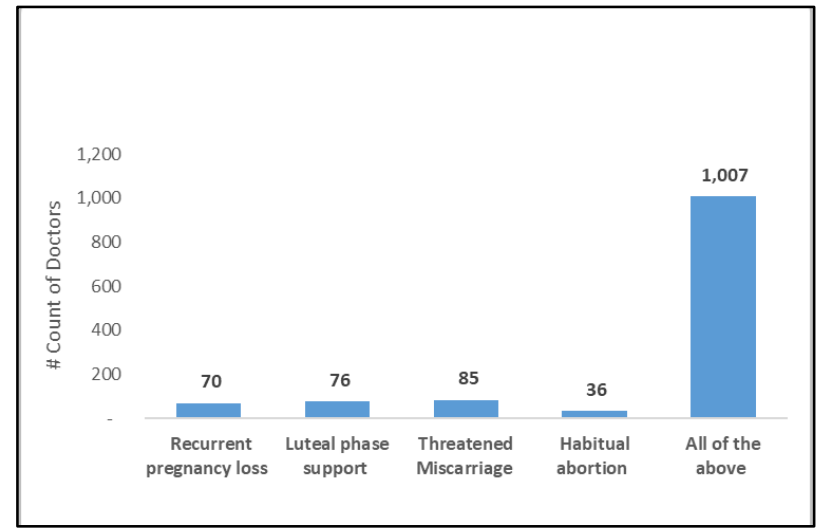

Figure 1: Most suitable conditions for use of dydrogesterone.

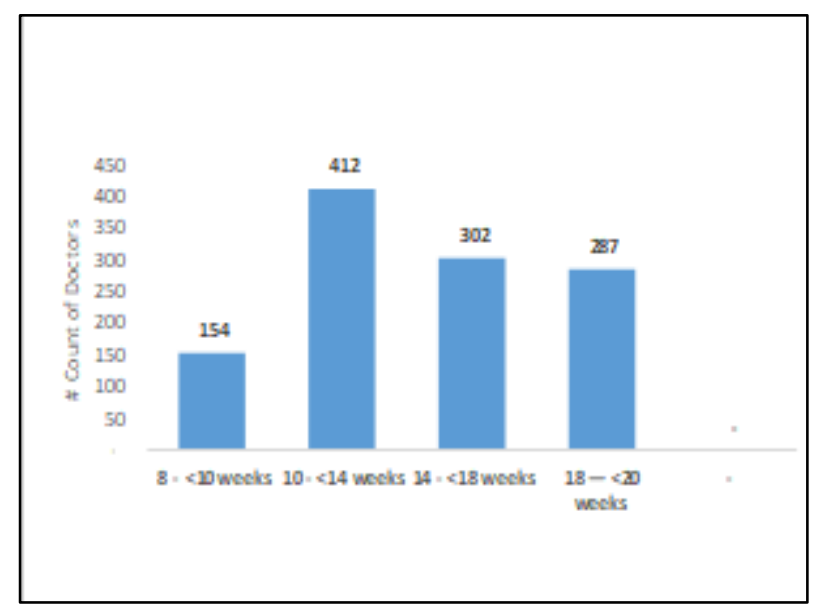

Figure 2: Average duration of dydrogesterone therapy in threatened abortion.

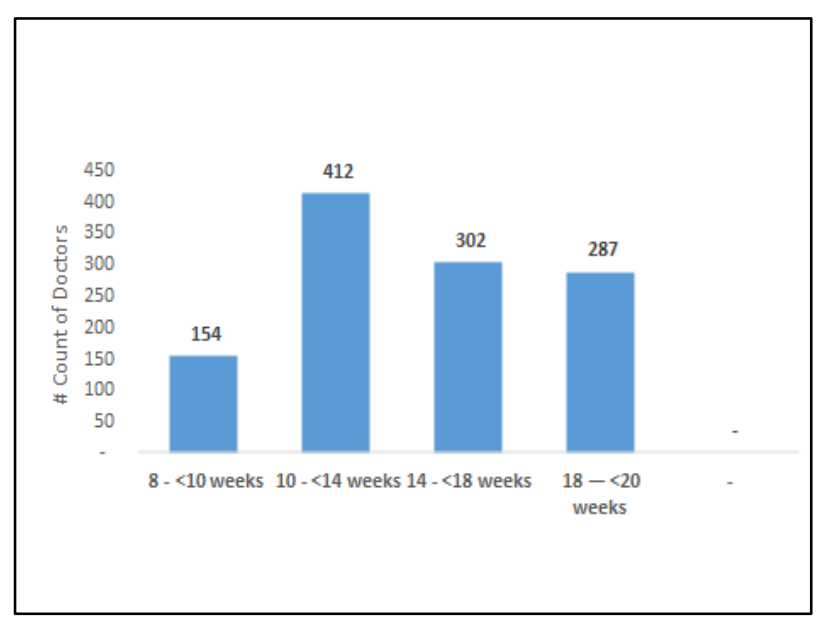

Figure 3: Average duration of dydrogesterone used in of recurrent miscarriage.

Majority of doctors i.e. $817 \quad(72 \%)$ reported high bioavailability, higher compliance, low side effects and better quality of life as advantages of dydrogesterone over micronized progesterone (Figure 6). Out of all participants, the indigenously developed product was the 
most preferred or preferred choice of around 897 (81\%) of gynaecologists (table 2). Poor tolerability, compliance and lower efficacy were the major limitations for use of micronized progesterone reported by 743 (68\%) gynaecologists.

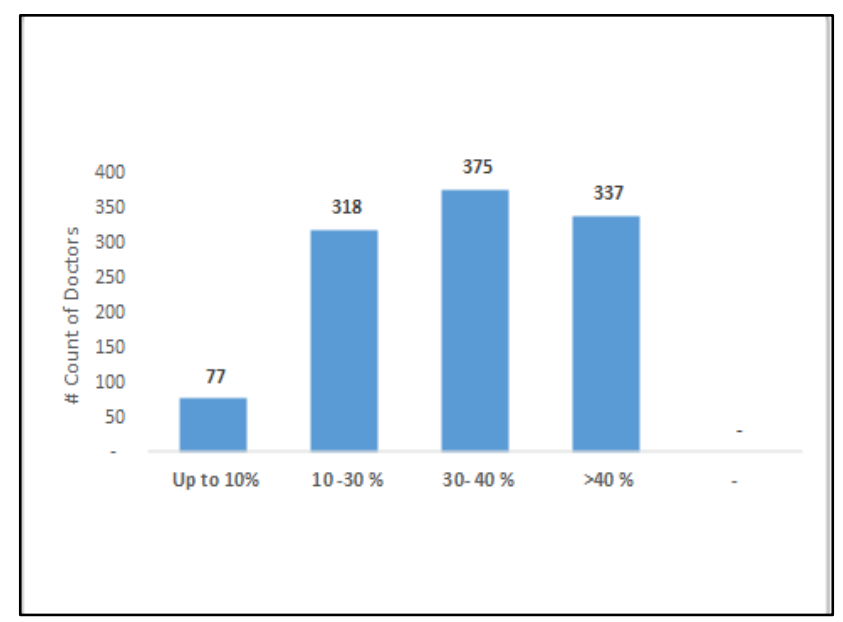

Figure 4: Average clinical pregnancy rate noticed at 12 weeks of dydrogesterone.

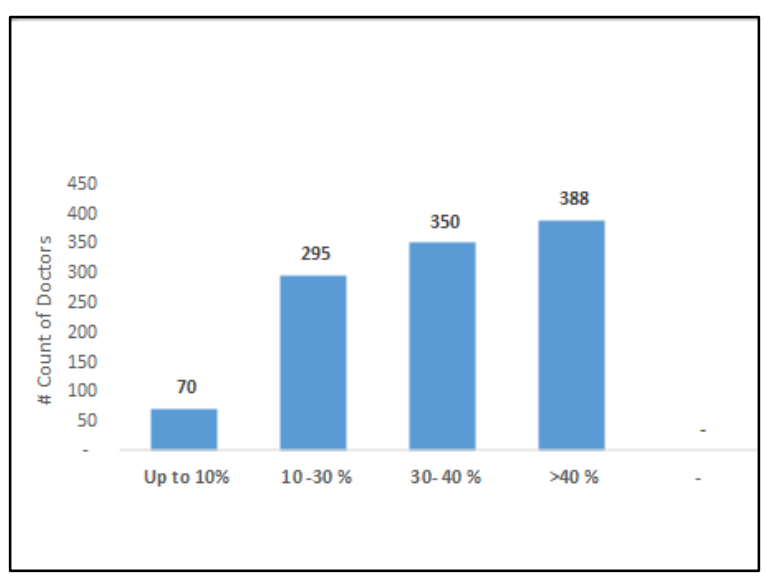

Figure 5: Average live birth rate observed after 12 weeks of dydrogesterone usage.

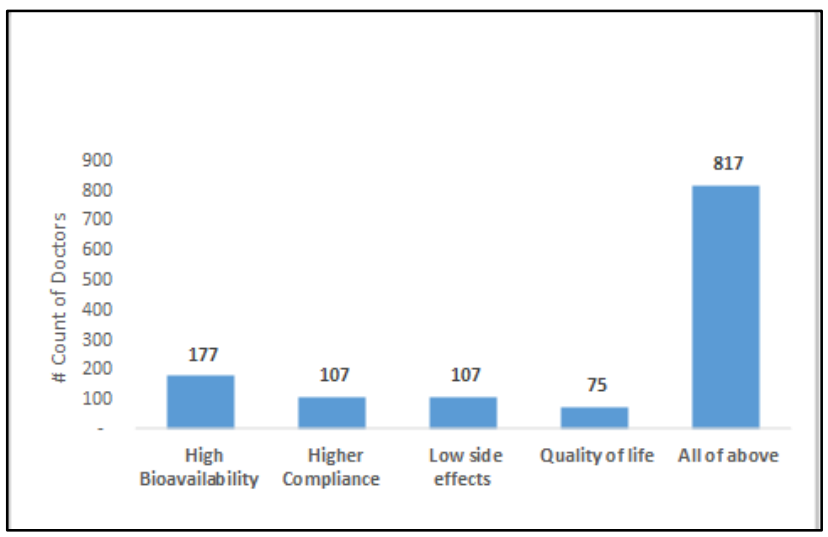

Figure 6: Advantages of dydrogesterone over natural micronized progesterone.

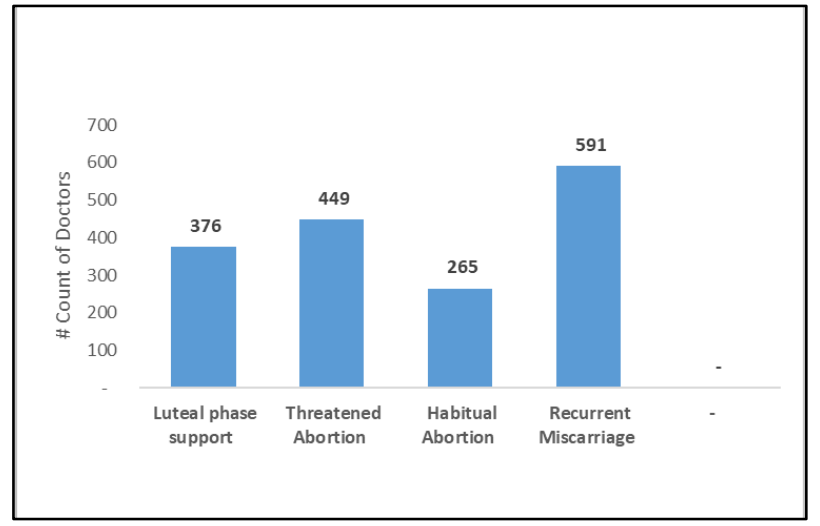

Figure 7: Co-administration of dydrogesterone and natural micronized progesterone in different indications.

Almost $771(70 \%)$ of doctors preferred to use dydrogesterone along with micronized progesterone. Dydrogesterone and micronized progesterone were preferred to be co-administered in recurrent miscarriage, threatened abortion and luteal phase support by $54 \%, 41 \%$ and $35 \%$ of doctors respectively (Figure 7 ). In this survey the quality of product and patient related outcomes were found to be two most important factors for selecting dydrogesterone by $514 \quad(46 \%)$ and $478 \quad(43 \%)$ gynaecologists respectively (Table 3 ). Whereas cost was not considered as an important Table 3.

\section{DISCUSSION}

Dydrogesterone has been marketed since the 1960s and has been extensively used worldwide for the treatment of threatened miscarriage and recurrent miscarriage, as well as for luteal phase support in the setting of infertility. ${ }^{7}$ Similar findings were observed in this survey wherein the substantial proportion of Indian gynecologists i.e. $87 \%$ reported to use dydrogesterone in women with recurrent pregnancy loss, habitual abortion, threatened abortion and for luteal phase support.

Many reports suggest that oral administration is most convenient for patients over intravaginal application and similar tends were observed in this survey. ${ }^{7-10}$ The oral progesterone and its derivative was preferred by around $42 \%$ of the doctors while only $7 \%$ and $3 \%$ of doctors preferred to use vaginal and injectable progesterone respectively.

Clinical studies have shown that oral dydrogesterone has a good benefit-risk profile, comparable to that of micronized vaginal progesterone. ${ }^{11}$ In this survey high bioavailability, high compliance, low side effects and better quality of life were reported as advantages of dydrogesterone over micronized progesterone by $72 \%$ of doctors. While poor tolerability, compliance and lower efficacy were reported as major limitations of micronized progesterone by $68 \%$ of doctors. In terms of efficacy of dydrogesterone in comparison to MVP, the results of 2013 
Cochrane Systematic Review suggests that dydrogesterone may be more effective than vaginal micronized progesterone in preventing miscarriage $(8.0 \%$ and $15.7 \%$ of women miscarried, respectively). ${ }^{12}$ While in the landmark trials like Lotus I and Lotus II it was demonstrated that oral dydrogesterone was non-inferior to micronized vaginal progesterone. ${ }^{13,14}$ Both the Lotus I and Lotus II studies have also demonstrated that oral dydrogesterone and MVP had comparable safety and tolerability profiles. In this survey, majority of the Indian gynaecologists reported that the average clinical pregnancy rate noted at 12 weeks after dydrogesterone usage is around $40 \%$ and around $30 \%$ of doctors noted more than $40 \%$ of clinical pregnancy rate after dydrogesterone usage.

The live birth rate noticed after dydrogesterone usage was also around $40 \%$ by almost $35 \%$ of doctors. Interestingly, almost $70 \%$ of Indian gynaecologist reported to use dydrogesterone along with micronized progesterone. The most common indications reported for co-administration of dydrogesterone and micronized progesterone were recurrent miscarriage, threatened abortion and luteal phase support reported by $54 \%, 41 \%$ and $35 \%$ of doctors respectively.

In the current survey, on points of clinical utility of dydrogesterone, $10 \mathrm{mg}$ twice daily was the most commonly preferred dosage by $823 \quad(73 \%)$ of gynecologists. In women with recurrent miscarriage, 52\% of doctors preferred to continue treatment with dydrogesterone for up to 18 to 20 weeks. While in cases of threatened abortion, near about $42 \%$ of the doctors reported to use dydrogesterone up to 14 weeks and $33 \%$ of doctors preferred to use dydrogesterone till 18 weeks in women with threatened abortion.

Another interesting finding of this survey was that the quality of product and patient related outcomes were found to be two most important factors for selecting dydrogesterone by $514 \quad(46 \%)$ and $478 \quad(43 \%)$ gynaecologists respectively, whereas cost was not considered as an important factor for selecting dydrogesterone.

Pan-India coverage and participation of a large number of gynaecologists are some of the strengths of this study. The present KAP study was cost-effective and the results were based on real life experiences. This study/survey has limitations which are applicable to a KAP study. A questionnaire reveals what is ticked but not necessarily what is actually practiced. Also, fixed number of questions with predefined options and recall bias were another limitations of the study. Present questionnaire was designed by authors and was not validated. This was designed to match observations in clinical practice. Questionnaire was based on a subjective opinion. Nevertheless, this was an attempt to understand the knowledge, attitude and practice of Indian gynaecologists towards use of dydrogesterone in clinical practice which revealed some known and some new interesting facts. However, these findings must be considered cautiously and confirmed by clinical studies.

\section{CONCLUSION}

The present KAP survey highlights that effectiveness and tolerability of Dydrogesterone is valued by many Indian gynaecologists which accounts for its robust clinical utility.

\section{ACKNOWLEDGEMENTS}

The authors gratefully acknowledge and thank the 1168 Gynaecologist across India who participated in this survey. Authors also acknowledge and thank to Dr. Onkar Swami for his guidance for developing this manuscript and $\mathrm{Mr}$. Vikas Raj and Mr. Unmesh Birje for providing the administrative support for the conduct of this survey.

\section{Funding: No funding sources}

Conflict of interest: None declared

Ethical approval: The study was approved by the Institutional Ethics Committee

\section{REFERENCES}

1. Schindler AE. First trimester endocrinology: consequences for diagnosis and treatment of pregnancy failure. Gynecol Endocrinol. 2004;18:517.

2. Szekeres-Bartho J, Barakonyi A, Par G. Progesterone as an immunomodulatory molecule. Int Immunopharmacol. 2001;1:1037-48.

3. Schindler AE. Progestational effects of dydrogesterone in vitro, in vivo and on the human endometrium. Maturitas. 2009;65:S3-S11.

4. de Lignie `res B. Oral micronized progesterone. Clin Ther. 1999;21:41-60.

5. Di Renzo GC, Mattei A, Gojnic M, Gerli S. Progesterone and pregnancy. Curr Opin Obstet Gynecol. 2005;17:598-600.

6. Chakravarty BN, Shirazee HH, Dam P. Oral dydrogesterone versus intravaginal micronised progesterone as luteal phase support in assisted reproductive technology (ART) cycles: results of a randomised study. J Steroid Biochem Mol Biol. 2005;97:416-20.

7. Georg G, Christophe B, Herman T. Oral dydrogesterone for luteal phase support in fresh in vitro fertilization cycles: a new standard? Fertility and Sterility®. 2018;109:5.

8. Bingham JS. Single blind comparison of ketoconazole $200 \mathrm{mg}$ oral tablets and clotrimazole $100 \mathrm{mg}$ vaginal tablets and $1 \%$ cream in treating acute vaginal candidosis. Br J Vener Dis. 1984;60:175-7.

9. Arvidsson C, Hellborg M, Gemzell-Danielsson K. Preference and acceptability of oral versus vaginal administration of misoprostol in medical abortion 
with mifepristone. Eur J Obstet Gynecol Reprod Biol. 2005;123:87-91.

10. Chakravarty BN, Shirazee HH, Dam P, Goswami SK, Chatterjee R, Ghosh S. Oral dydrogesterone versus intravaginal micronised progesterone as luteal phase support in assisted reproductive technology (ART) cycles: results of a randomised study. J Steroid Biochem Mol Biol. 2005;97:416-20.

11. Barbosa MWP, Silva LR, Navarro PA, Ferriani RA, Nastri CP, Martins WP. Dydrogesterone vs progesterone for luteal-phase support: systematic review and meta-analysis of randomized controlled trials. Ultrasound Obstet Gynecol. 2016;48:161-70.

12. Manish PR, Gopeenathan P, Gopinath P.M, Das SK, Meenakshi S, Veena S. Evaluating the clinical efficacy and safety of progestogens in the management of threatened and recurrent miscarriage in early pregnancy- A review of the literature. Indian
Journal of Obstetrics and Gynecology Research. 2016;3(2):157-66.

13. Tournaye H, Sukhikh GT, Kahler E, Griesinger G. A Phase III randomized controlled trial comparing the efficacy, safety and tolerability of oral dydrogesterone versus micronized vaginal progesterone for luteal support in in-vitro fertilization. Human Reproduction. 2017;32(5):1019-27.

14. Griesinger G, Blockeel G, Sukhikh GT, Patki A, Dhorepatil B, Yang DZ et al. Oral dydrogesterone versus intravaginal micronized progesterone gel for luteal phase support in IVF: a randomized clinical trial. Human Reproduction. 2018;33(12):2212-21.

Cite this article as: Khanna G, Dabade M, Dutta S, Deshpande N, Mane G, Shah C et al. Dydrogesterone usage pattern in India: a knowledge, attitude and practice survey among Indian gynaecologists. Int J Reprod Contracept Obstet Gynecol 2021;10:3793-8. 